\title{
Nutritional Studies on Desulfovibrio desulfuricans using Chemically Defined Media
}

\author{
By RHONA MACPHERSON AND J. D. A. MILLER \\ National Chemical Laboratory, Teddington, Middlesex
}

(Received 17 September 1962)

\begin{abstract}
SUMMARY
A non-precipitating chemically defined medium containing lactate, sulphate and other inorganic salts supported repeated subculture of Desulfovibrio desulfuricans, strain Hildenborough; yields of bacteria were comparable with those obtained in media containing yeast extract or peptone. Addition of yeast extract, amino acid mixtures or ATP to the defined medium increased the crop. Growth on other organic substances was poorer than on lactate; amino acids were less efficient nitrogen sources than ammonia. Pyruvate served as electron acceptor for hydrogen uptake by resting organisms but did not support growth in sulphate-free medium.
\end{abstract}

\section{INTRODUCTION}

Numerous strains of sulphate-reducing bacteria representing three or more species have now been isolated, yet in relatively few cases have critical studies of their growth and nutrition been made. Butlin, Adams \& Thomas (1949) developed a complex medium (medium $\mathbf{C}$ ) giving rapid and abundant growth of unnamed strains of sulphate reducers, and demonstrated an iron requirement. Autotrophic growth in a chemically defined medium was claimed. Postgate (1951, 1953) obtained poor growth of Desulfovibrio desulfuricans strain Hildenborough in a simple glucose ammonia medium incorporating cysteine; the yield was improved somewhat by adding serine, ornithine and isoleucine, and markedly by adding yeast extract. Cysteine was shown by Grossman \& Postgate (1953) to act by poising the redox potential and to be replaceable by $\mathrm{Na}_{2} \mathrm{~S}$. A peptone yeast-extract medium supporting massive growth of strain Hildenborough was devised (Postgate, 1951). This strain, one of those used by Butlin et al. (1949), was recently proved incapable of autotrophic growth (Mechalas \& Rittenberg, 1960; Postgate, 1960), whereas an unnamed strain was stated by Sorokin (1960) to grow autotrophically in a defined medium. Autotrophic incorporation of $\mathrm{CO}_{2}$ by strain Sylt 3 in presence of yeast extract was claimed by Stüven (1960). Grossman \& Postgate (1955), who reviewed the earlier work on utilization of carbon sources, reported growth of strain El Agheila $\mathbf{Z}$ on malate, succinate, lactate or pyruvate in a medium containing yeast extract. Carbon sources were also reviewed by Postgate (1959), who pointed out that an unfavourable $E_{h}$ value, and marginal growth on impurities, may give rise to conflicting observations. Stimulatory effects in defined media by biotin (Wikén \& Ghose, 1954) and ATP (Kadota \& Miyoshi, 1960) have been reported. Studies on the inorganic nutrition of marine strains have been made by Kimata, Kadota, Hata \& Tajima $(1955 b)$ and Hata $(1960 a, b)$ with a medium containing desalted 
peptone; certain strains were unable to utilize inorganic nitrogen compounds (Kimata, Kadota \& Hata, 1955a). Postgate (1956b) found that the halophile El Agheila $Z$ required iron for utilization of sulphate, but not pyruvate, as terminal electron acceptor.

Certain of the contradictory reports on nutrition and metabolism of the sulphate reducers may reflect genuine differences between strains, while others may be attributable to ill-defined conditions of cultivation (e.g. presence of yeast extract or peptone; absence of $E_{h}$ control). The work reported here was concerned with the development of a non-precipitating chemically defined medium and its use in nutritional studies on Hildenborough, a strain on which several physiological and biochemical studies have been reported.

\section{METHODS}

Organism. Desulfovibrio desulfuricans strain Hildenborough (National Collection of Industrial Bacteria, NCIB, no. 8303), purified by Postgate (1953) from an impure culture obtained from Wealden clay at Hildenborough, Kent, was stored in a lyophilized condition. Frequent tests were made on subcultures for anaerobic (Postgate, 1953) and aerobic contaminants.

Preparation of media. All glassware was cleaned in chromic acid (potassium dichromate + sulphuric acid). Media were prepared from analytical (Analar) grade chemicals where available, and Pyrex-distilled water. ATP was obtained from Sigma Chemical Co. (St Louis, U.S.A.). Chemicals of doubtful purity were purified by recrystallization. Lactic acid and yeast extract were incorporated into media before autoclaving at $115^{\circ}$ for 20 min.: the fall in $\mathrm{pH}$ during autoclaving indicated dissociation of the dimer of lactic acid. All other organic substances were sterilized separately in solution by passing through sterile Oxoid membrane filter disks, grade AP, $4 \mathrm{~cm}$. diam. (Oxo Ltd., London E.C. 4), supported in glass Seitz-type filters. Solutions of ferrous salts formed precipitates on autoclaving or filtering through grade EKS Seitz filter pads. Membrane-filtered solutions in $2.5 \mathrm{~mm}-\mathrm{H}_{2} \mathrm{SO}_{4}$ showed no precipitation during storage for two months at $3^{\circ}$ : stock solutions of $\mathrm{FeSO}_{4}$ were therefore prepared in this manner. In all cases media were adjusted to $\mathrm{pH} 7 \cdot 2-7 \cdot 4$ with sterile $15 \%(\mathrm{w} / \mathrm{v}) \mathrm{NaOH}$ solution after autoclaving, using bromothymol blue indicator.

Cultivation. Lyophilized bacteria were inoculated initially into the medium $\mathrm{C}$ of Butlin et al. (1949); thereafter subcultures were made weekly into the experimental defined medium and growth experiments inoculated from these stock cultures. During later work stock cultures were maintained in the final version of this medium (the 'standard medium', the development of which is described in Results): lactic acid, $100 \mathrm{~mm}$; $\mathrm{KH}_{2} \mathrm{PO}_{4}, 2.5 \mathrm{~mm} ; \mathrm{NH}_{4} \mathrm{Cl}, 10 \mathrm{~mm} ; \mathrm{Na}_{2} \mathrm{SO}_{4}, 50 \mathrm{~mm}$; $\mathrm{CaCl}_{2}$, $0.5 \mathrm{~mm} ; \mathrm{MgSO}_{4} .7 \mathrm{H}_{2} \mathrm{O}, 0.25 \mathrm{~mm}$; trace elements $\mathrm{B}, \mathrm{Co}, \mathrm{Cu}, \mathrm{Mn}, \mathrm{Mo}, \mathrm{Zn}$ each $0.05 \mathrm{mg}$. $/ 1$. The medium was adjusted to about $\mathrm{pH} \mathrm{6.5}$ with $\mathrm{NaOH}$ and autoclaved. When cool, sterile $\mathrm{FeSO}_{4} \cdot 7 \mathrm{H}_{2} \mathrm{O}$ solution was added to $25 \mu \mathrm{M}$ and the medium adjusted to $\mathrm{pH} 7 \cdot \mathbf{2}-\mathbf{7} \cdot \mathbf{4}$.

Both stock and experimental cultures were grown in Pyrex test tubes plugged with cotton-wool and containing $10 \mathrm{ml}$. medium. Cultures were incubated at $30^{\circ}$ in McIntosh \& Fildes' anaerobic jars under an atmosphere of $99 \% \mathrm{H}_{2}+1 \% \mathrm{CO}_{2}$ $(\mathrm{v} / \mathrm{v})$. Except as indicated below, $1 \cdot 0 \mathrm{~mm}-\mathrm{Na}_{2} \mathrm{~S}$ was added immediately before 
inoculation to poise the redox potential at about $-\mathbf{3 0 0} \mathrm{mV}$. Triplicate cultures were used in all experimental treatments.

Estimation of growth. Attempts to observe early exponential growth in studies on nutrient concentrations by haemacytometer counts and optical density readings gave meaningless results. Dry wt. determinations on large samples withdrawn from $500 \mathrm{ml}$. cultures gave somewhat better results (typical standard deviations of a single determination on each of three cultures were $73.5 \%$ after $24 \mathrm{hr}$., $35.8 \%$ after $48 \mathrm{hr}$., $21.4 \%$ after $72 \mathrm{hr}$., and $6.0 \%$ after $96 \mathrm{hr}$. of incubation); however, this method was unsuitable for comparing growth in large numbers of cultures. Late exponential and post-exponential growth were therefore estimated by the optical density method described by Postgate (1951) and, when required, equivalent values for dry wt. organism $/ \mathrm{ml}$. suspension were read from a calibration curve. $\mathrm{Na}_{2} \mathrm{~S}$ was omitted from these cultures owing to its darkening effect, and neither cysteine nor ascorbic acid was added since they might serve as nutrients. Instead, a relatively large inoculum $(0 \cdot 2 \mathrm{ml}$.) from a 4-day-old stock culture was used: this was of sufficient size to prevent failures of growth while not giving excessive carry-over of nutrients, and the maximum standard deviation of the results obtained on days 3-5 (Figs. 1-3) was 7.9\%.

Growth in tubes containing $\mathrm{Na}_{2} \mathrm{~S}$ was estimated by eye when it appeared to be complete; cultures showing doubtful growth were examined microscopically.

Manometry. Measurement of hydrogenase activity was made at $32^{\circ}$ following the procedure of Littlewood \& Postgate (1956) except that $15 \%$ (w/v) KOH was used as absorbent for $\mathrm{H}_{2} \mathrm{~S}$ and $\mathrm{CO}_{2}$.

\section{RESULTS}

\section{Development of the 'standard medium'}

$A$ non-precipitating defined medium. Medium C of Butlin et al. (1949) had the disadvantages for our purposes that it formed a precipitate when autoclaved, thus losing an uncertain proportion of nutrients (including $\mathrm{Fe}^{2+}$; Dr J. R. Postgate, personal communication), it contained yeast extract, and sodium lactate which is not available in Analar grade, and its content of lactate and sulphate were not optimal (Dr J. R. Postgate, personal communication). The medium was modified in the following ways. The major nutrients were supplied as Analar reagents and their concentrations adjusted to molarities for convenience. Thus 50 mm-lactic acid, $2.5 \mathrm{~mm}-\mathrm{KH}_{2} \mathrm{PO}_{4}, 0.5 \mathrm{~mm}-\mathrm{CaCl}_{2}$ and $25 \mathrm{~mm}-\mathrm{Na}_{2} \mathrm{SO}_{4}$ were used. $10 \mathrm{~mm}-\mathrm{NH}_{4} \mathrm{Cl}$ was tentatively supplied as sole nitrogen source despite the findings of Kimata et al. (1955a) that certain strains of Desulfovibrio desulfuricans cannot utilize ammonia. To minimize precipitation the divalent cation content was decreased by using $0 \cdot 25 \mathrm{mM}^{-\mathrm{MgSO}_{4}} \cdot 7 \mathrm{H}_{2} \mathrm{O}$ : there appear to be no published results which justify the use of $8.13 \mathrm{mg}$.-ion $\mathrm{Mg}^{2+} / \mathrm{l}$. in medium $\mathrm{C}$. In addition, an arbitrary trace element mixture was incorporated giving a final concentration of $0.05 \mathrm{mg} . / 1$. each of $\mathrm{B}, \mathrm{Co}$, $\mathrm{Cu}, \mathrm{Mn}, \mathrm{Mo}$ and $\mathrm{Zn}$. This medium, adjusted to about $\mathrm{pH} 6.5$ with $\mathrm{NaOH}$ and autoclaved at $115^{\circ}$ for 20 min., did not precipitate. After addition of sterile $\mathrm{FeSO}_{4}$

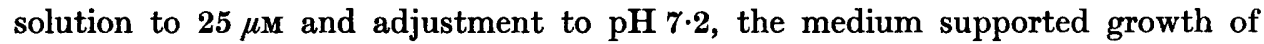
strain Hildenborough through serial subculture, giving crops equivalent to about $380 \mu$ g. dry wt./ml. suspension. 
Effect of concentration of the defined medium. To determine whether the over-all concentration of the defined medium was optimal, growth was observed at $\frac{1}{2}, 1,2$ and 4 times the original concentration. The results (Fig. 1) show that medium $\times 4$ was inhibitory, while growth in medium $\times 2$, though eventually outstripping that

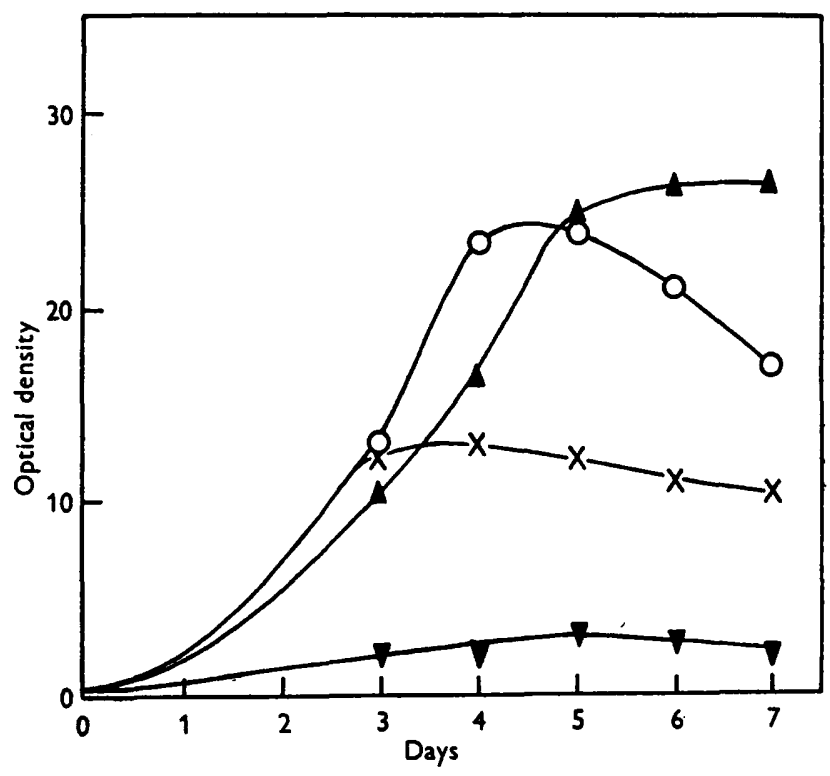

Fig. 1. Growth of $D$. desulfuricans strain Hildenborough in the experimental defined medium at original concentration $(O)$ and at $\frac{1}{2}(X), 2(\Delta)$ and $4(\nabla)$ times this concentration.

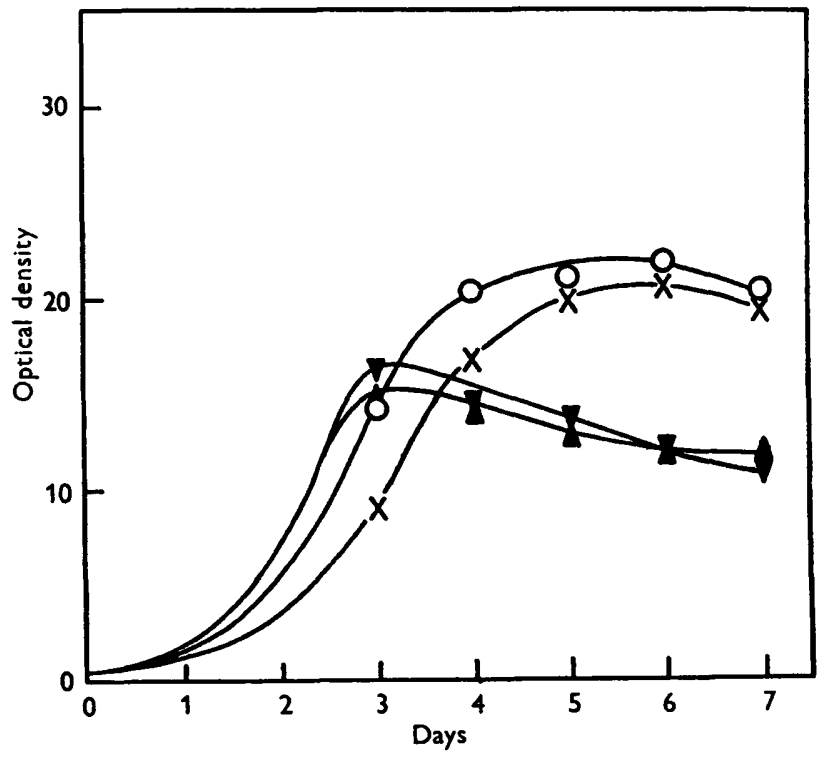

Fig. 2. Effect on growth of $D$. desulfuricans strain Hildenborough of decreasing one component of the defined medium by one-half. $O=$ full medium, $x=\frac{1}{2}-\mathrm{FeSO}_{4}$, $\Delta=\frac{1}{2}$-lactate, $\nabla=\frac{1}{2} \mathrm{Na}_{2} \mathrm{SO}_{4}$. 
in $\times 1$, was slower, suggesting an unfavourably high osmotic pressure or a toxic level of a nutrient. It thus appeared that growth might be more effectively improved by an increase in the concentration of one or two nutrients.

Effect of concentration of individual components. In the experiment illustrated in Fig. 2 one of the major nutrients (lactate, $\mathrm{KH}_{2} \mathrm{PO}_{4}, \mathrm{NH}_{4} \mathrm{Cl}, \mathrm{MgSO}_{4}, \mathrm{CaCl}_{2}$, $\mathrm{Na}_{2} \mathrm{SO}_{4}$ or $\mathrm{FeSO}_{4}$ ) was decreased to one-half of its original concentration, all others being present at full concentration. For the sake of clarity the growth curves for $\frac{1}{2}-\mathrm{KH}_{2} \mathrm{PO}_{4}, \frac{1}{2}-\mathrm{NH}_{4} \mathrm{Cl}, \frac{1}{2}-\mathrm{MgSO}_{4}$ and $\frac{1}{2}-\mathrm{CaCl}_{2}$ are omitted from the figure; they were all very close to that for full medium. The results suggested that growth in the full medium was limited by both lactate and sulphate. Thus the lactate and sulphate

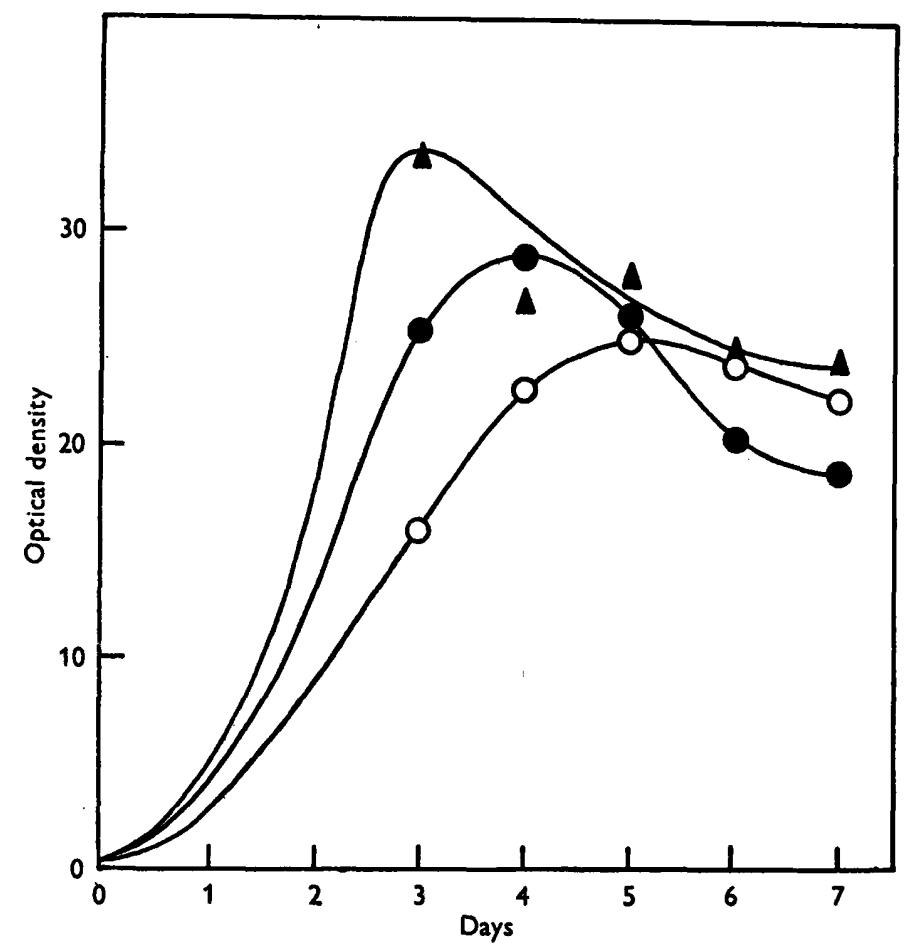

Fig. 3. Stimulation of the growth of $D$. desulfuricans strain Hildenborough in the standard medium by yeast extract. $O=$ standard medium, $\Delta=$ standard medium + $0 \cdot 1 \%(w / v)$ yeast extract, $O=$ original defined medium.

concentrations were separately increased $1 \frac{1}{2} \times, 2 \times$ and $3 \times$ in all combinations. It appeared that $2 \times$ lactate $+2 \times$ sulphate produced the most rapid growth; $3 \times$ lactate $+2 \times$ sulphate gave a slightly greater crop but a much lower growth rate. The medium with $2 \times$ lactate $+2 \times$ sulphate was therefore selected as the standard medium for all further experimentation with the Hildenborough strain and for maintenance of stock cultures. Details of preparation are given in Methods.

Yields equivalent to about $480 \mu \mathrm{g}$. dry wt. bacteria $/ \mathrm{ml}$. suspension are obtained in the standard medium. Soon after the onset of the stationary phase the number of bacteria remaining in suspension appears from microscopic examination greatly to decrease, while mucin containing large numbers of embedded organisms is precipitated, so that optical density determinations become misleading. 
Perpetuation of strain Hildenborough in the standard medium. The organism has been serially subcultured more than 50 times in the standard medium without noticeable decrease in rate or abundance of growth. Inoculations of $2 \mu \mathrm{l}$. (equivalent to about $0.8 \mu \mathrm{g}$. dry wt. organism or a loopful of culture) from young cultures into $50 \mathrm{ml}$. medium have always in our experience produced normal growth provided that $\mathrm{Na}_{2} \mathrm{~S}$, cysteine or ascorbic acid is incorporated. Lyophilized organisms originally grown in the medium can be successfully revived in it.

\section{Effect of nitrogenous supplements in the standard medium}

Typical growth in the standard medium and the original defined medium is shown in Fig. 3 which also illustrates the stimulatory effect of adding $1.0 \mathrm{~g} . / \mathrm{l}$. Difco yeast extract (the concentration in medium C) to the standard medium. Since the lactate and ammonia concentrations in the standard medium were considered to be optimal, it was inferred that certain substances present in yeast extract might constitute more acceptable carbon or nitrogen sources, or serve as growth factors. The effects of the following supplements were therefore examined: Postgate's (1951) mixture of serine + ornithine + isoleucine; the mixture of 18 amino acids employed by Kadota \& Miyoshi (1960) as a nitrogen source; 18 amino acids + 0.1 g. ATP/l. (Kadota \& Miyoshi, 1960); ATP alone. Table 1 shows that ATP, as well as mixtures of metabolites, markedly improve growth in the standard medium.

\section{Table 1. Maximum growth of Desulfovibrio desulfuricans strain Hildenborough in standard medium with various nitrogenous supplements}

Optical densities were determined daily, and the maximum values converted to dry wt./ml. suspension from a calibration curve.

\begin{tabular}{lc}
\multicolumn{1}{c}{ Supplement } & $\begin{array}{c}\text { Growth } \\
(\mu \mathrm{g} . \text { dry wt. } \\
\text { bacteria/ml. })\end{array}$ \\
None & 470 \\
Serine +ornithine + isoleucine (each 1.0 g. $/ 1)$. & 500 \\
18 amino acids & 620 \\
18 amino acids + ATP 0.1 g./1.) & 690 \\
ATP (0.1 g./1.) & 630 \\
Yeast extract (1.0 g./1.) & 560
\end{tabular}

\section{Tests of alternative nutrients and electron acceptors}

Carbon sources. Substrates to be tested as carbon sources were added to lactatefree standard medium so as to give $150 \mathrm{mg}$.-atom $\mathrm{C} / \mathrm{l}$., no allowance being made for the partial unavailability of DL-forms. Difco yeast extract was tested at $1.0 \mathrm{~g}$. $/ \mathrm{l}$. Toxicity tests (tubes containing lactate + substrate under trial) were also inoculated; a few amino acids proved inhibitory and their concentration was subsequently halved. Inoculation was with bacteria washed in $\mathrm{C}$-free medium. Despite addition of $\mathrm{Na}_{2} \mathrm{~S}$, only pyruvate, the monohydric alcohols and a few sugars supported growth. A 'training' method was therefore tried, in which the media under test were initially supplemented with lactate. Subcultures were made into media without a lactate supplement, and substrates were considered to be utilized when growth continued thereafter at an apparently unimpaired rate through five subcultures. In this way growth was obtained in several more substrates as shown in Table 2, though lags 
of up to 5 weeks occurred in some cases before growth appeared in the first subculture into lactate-free medium, and growth was only marginal (denoted \pm ) in certain others. The first attempt to 'train' the organism to utilize glycerol failed, though at a second attempt fairly heavy growth occurred. No substrate supported such abundant growth as lactate.

Table 2. Utilization of carbon sources by Desulfovibrio desulfuricans strain Hildenborough

Substrates were at a concentration giving $150 \mathrm{mg}$.-atom C/l. unless otherwise stated.

Glucose
Fructose
Lactose
Maltose
Sucrose
Methanol
Ethanol
Propanol
Glycerol
Acetate
Citrate
Lactate
Pyruvate
Oxaloacetate
Malate
Fumarate
Succinate
Succinamide
DL-alanine
L-arginine HCl

+
+
+
+
++
+
+
+
++
-
-
++
++
+
-
\pm
\pm
\pm
-

L-aspartic acid
L-asparagine
L-citrulline
L-cysteine HCl
L-cystine
L-glutamic acid
L-glutamine
Glycine
L-histidine HCl
DL-isoleucine*
L-leucine
L-lysine HCl
DL-methionine*
L-phenylalanine*
L-proline
DL-serine
DL-threonine*
DL-tryptophane
DL-valine
Yeast extract $(1 \cdot 0 \mathrm{~g} \cdot / 1$.)
tom C/l.

Nitrogen sources. The mixture of 18 amino acids as prescribed by Kadota \& Miyoshi (1960), and the individual acids at $5 \mathrm{mg}$--atom N/l., were tested as nitrogen sources in ammonia-free standard medium; asparagine, citrulline and cysteine were also tested. Growth in the mixture was about as abundant as in 5 mM- $\mathrm{NH}_{4} \mathrm{Cl}$, while all the individual amino acids except cysteine, glycine, histidine, methionine and tyrosine supported slight growth.

Organic terminal electron acceptors. Pyruvate and fumarate at non-toxic concentration ( $50 \mathrm{~mm}$ ), in standard medium without $\mathrm{Na}_{2} \mathrm{SO}_{4}$ and with one-half of the normal $\mathrm{MgSO}_{4}$ concentration, were tested for ability to serve as terminal electron acceptors. No growth occurred, though the abundant growth of Escherichia coli (NCIB, no. 7271) obtained in these media under aerobic conditions indicated that the sulphate concentration was sufficient for assimilatory metabolism. Manometric experiments showed that washed organisms in non-nutrient buffer absorbed hydrogen for the reduction of $15 \mathrm{~mm}$-sodium pyruvate, $-Q_{\mathrm{H}_{2}}=23.5 \mu \mathrm{l} . / \mathrm{mg}$. dry wt. $/ \mathrm{hr}$. or about one-tenth of the value obtained with equimolar sulphate as electron acceptor. No detectable hydrogen uptake occurred with sodium fumarate. 


\section{DISCUSSION}

Kadota \& Miyoshi (1960) reported that they were unable to grow certain sulphatereducing bacteria in defined media unless abnormally large inocula were used or organic substances such as peptone, yeast extract or mixtures of amino acids added. For 'normal' growth Desulfovibrio desulfuricans strain Hildenborough required, in a basal ammonia-free medium containing lactate, ATP and mineral salts, the addition of peptones or $\mathbf{1 8}$ amino acids: growth was greatly diminished when five of the amino acids were omitted. The effect of adding an ammonium salt was not studied. Our experiments have shown that ammonia is a more acceptable nitrogen source for strain Hildenborough than organic nitrogen compounds. In this respect the organism appears to differ from the marine strains examined by Kimata et al. $(1955 a)$ which were unable to utilize ammonium salts. A lactate medium of suitable composition, containing no other organic substance and with ammonia as sole nitrogen source, supports vigorous growth through indefinite subculture and thus appears to be a complete medium for the Hildenborough strain. Small transfers ( $2 \mu$ l. into $50 \mathrm{ml}$., the smallest tested by us) grow normally in such a medium poised at a suitable redox potential. The addition of mixtures of metabolites such as yeast extract or an amino acid mixture to the standard defined medium stimulates growth, despite their being poor carbon sources. Nevertheless, the crop in the standard medium without any organic addition (about $480 \mu \mathrm{g}$. dry wt. organism/ml. suspension) compares favourably with the value of $300 \mu \mathrm{g} . / \mathrm{ml}$. in medium $\mathrm{C}$ and 500 $520 \mu \mathrm{g} . / \mathrm{ml}$. in medium $\mathrm{C}$ with additional lactate and sulphate (Dr J. R. Postgate, personal communication). The growth of Hildenborough, like that of the halophile Maizuru 1 (Kadota \& Miyoshi, 1960) is stimulated by ATP in defined media.

The survey of substrate utilization by strain Hildenborough presented difficulty. Postgate (1959) drew attention to the necessity of poising the redox potential especially of media to which the organism is unaccustomed; even so, in our experience, cases of apparent utilization by the 'training' technique are not always repeatable, or growth dies out after a few subcultures. Growth on most carbon sources is extremely scanty, and may take several weeks to appear, so that marginal growth on impurities cannot always be ruled out. Thus utilization of substratesother than acetate, the utilization of which by a sulphate reducer would be highly interesting (Selwyn \& Postgate, 1959)-does not promise to be a useful method of characterizing these organisms. The growth obtained with $1.0 \mathrm{~g}$. yeast extract/l. as carbon source (up to $120 \mu \mathrm{g}$. dry wt./ml.) indicates that reports of substrate utilization or 'autotrophic' growth by Desulfovibrio desulfuricans in media incorporating yeast extract should be viewed with caution. Several strains, chiefly halophilic, are able to dismute pyruvate in sulphate-free media (Postgate, 1952, 1956a). The Hildenborough strain has been shown to be incapable of growth by this means, in keeping with Postgate's (1952) findings. Neither has it the ability possessed by certain marine strains (Sisler \& ZoBell, 1951; Grossman \& Postgate, 1955) to reduce fumarate with hydrogen. There are thus some grounds for supposing that the Hildenborough strain may differ from marine strains nutritionally as well as in the ways described by Ochynski \& Postgate (1963). 
We are indebted to Dr J. R. Postgate, Dr G. H. Booth and our colleagues in the Microbiology Section for valuable discussions. The paper is published by permission of the Director, National Chemical Laboratory.

\section{REFERENCES}

Butlin, K. R., Adams, M. E. \& Thomas, M. (1949). The isolation and cultivation of sulphate-reducing bacteria. J. gen. Microbiol. 3, 46.

Grossman, J. P. \& Postgate, J. R. (1953). The cultivation of sulphate-reducing bacteria. Nature, Lond. 171, 600.

Grossman, J. P. \& Postgate, J. R. (1955). The metabolism of malate and certain other compounds by Desulphovibrio desulphuricans. J. gen. Microbiol. 12, 429.

HATA, Y. (1960a). Inorganic nutrition of marine sulfate-reducing bacteria. J. Shimonoseki Coll. Fish. 9, 347.

HATA, Y. (1960b). Influence of heavy metals upon the growth and the activity of the marine sulfate-reducing bacteria. J. Shimonoseki Coll. Fish. 9, 363.

Kadota, H. \& Mryoshi, H. (1960). A chemically defined medium for the growth of Desulfovibrio. Mem. Res. Inst. Fd Sci., Kyoto Univ. 22, 20.

Kimata, M., Kadota, H. \& Hata, Y. (1955a). Studies on the marine sulfate-reducing bacteria. IV. Nutritional requirements of marine sulfate-reducing bacteria (1). Bull. Jap. Soc. sci. Fish. 21, 229.

Kimata, M., Kadota, H., Hata, Y. \& Tajima, T. (1955b). Studies on the marine sulfatereducing bacteria. III. Influence of various environmental factors upon the sulfatereducing activity of marine sulfate-reducing bacteria (2). Bull. Jap. Soc. sci. Fish. 21, 113.

Littlewood, D. \& Postgate, J. R. (1956). Substrate inhibition of hydrogenase enhanced by sodium chloride. Biochim. biophys. Acta, 20, 399.

Mechalas, B. J. \& Rittenberg, S. C. (1960). Energy coupling in Desulfovibrio desulfuricans. J. Bact. 80, 501.

Ochynski, F. W. \& Postgate, J. R. (1963). Some biochemical differences between fresh water and salt water strains of sulphate-reducing bacteria. In Symposium on Marine Microbiology. Ed. by C. H. Oppenheimer. Springfield, U.S.A.: C. C. Thomas.

Postgate, J. R. (1951). On the nutrition of Desulphovibrio desulphuricans. J. gen. Microbiol. 5, 714.

Postgate, J. R. (1952). Growth of sulphate-reducing bacteria in sulphate-free media. Research, 5, 189.

Postgate, J. R. (1953). On the nutrition of Desulphovibrio desulphuricans: a correction. J. gen. Microbiol. 9, 440.

Postgate, J. R. $(1956 a)$. Iron and the synthesis of cytochrome $c_{3}$. J. gen. Microbiol. 15, 186.

Postgate, J. R. (1956b). Sulphate-reducing bacteria which are deficient in cytochrome. J. gen. Microbiol. 15, viii.

Postgate, J. R. (1959). Sulphate reduction by bacteria. Annu. Rev. Microbiol. 13, 505.

Postgate, J. R. (1960). On the autotrophy of Desulphovibrio desulphuricans. $Z$. allg. Mikrobiol. 1. 53.

Selwyn, S. C. \& Postgate, J. R. (1959). A search for the Rubentschikii group of Desulphovibrio. Antonie van Leeurvenhoek J. Microbiol. Serol. 25, 465.

Sisler, F. D. \& Zobell, C. E. (1951). Hydrogen utilization by some marine sulfatereducing bacteria. J. Bact. $62,117$.

Sorokin, Y. I. (1960). Utilization of the carbon in $\mathrm{CO}_{2}$ by Vibrio desulfuricans and certain heterotrophic bacteria. Doklady Akad. Nauk, U.S.S.R., biol. Sci. Sect. 132, 445.

Stüven, K. (1960). Beiträge zur Kenntnis der $\mathrm{CO}_{2}$ - und Lactatassimilation von Desulfovibrio aestuarii (van Delden) Kluyver und Van Niel. Arch. Mikrobiol. 36, 31.

WIKÉn, T. \& GHOSE, T. K. (1954). Stimulation of bacterial sulphate reduction by ( + )-biotin. Physiol. Plant. 7, 713. 